\title{
BMJ Open Patients' experiences of the choice of GP practice pilot, 2012/2013: a mixed methods evaluation
}

\author{
Stefanie Tan, Bob Erens, Michael Wright, Nicholas Mays
}

To cite: Tan S, Erens B, Wright M, et al. Patients' experiences of the choice of GP practice pilot, 2012/2013: a mixed methods evaluation. BMJ Open 2015;5:e006090. doi:10.1136/bmjopen-2014006090

- Prepublication history for this paper is available online. To view these files please visit the journal online (http://dx.doi.org/10.1136/ bmjopen-2014-006090).

Received 14 July 2014 Revised 14 November 2014 Accepted 20 January 2015

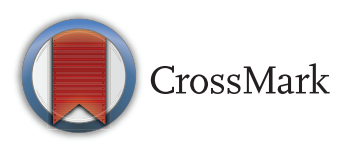

Policy Innovation Research Unit, Department of Health Services Research \& Policy, London School of Hygiene and Tropical Medicine, London, UK

Correspondence to Stefanie Tan;

Stefanie.Tan@|shtm.ac.uk

\section{ABSTRACT}

Objectives: To investigate patients' experiences of the choice of general practitioner (GP) practice pilot.

Design: Mixed-method, cross-sectional study. Setting: Patients in the UK National Health Service (NHS) register with a general practice responsible for their primary medical care and practices set geographic boundaries. In 2012/2013, 43 volunteer general practices in four English NHS primary care trusts (PCTs) piloted a scheme allowing patients living outside practice boundaries to register as an out of area patient or be seen as a day patient.

Participants: Analysis of routine data for 1108 out of area registered patients and 250 day patients; postal survey of out of area registered (315/886, 36\%) and day $(64 / 188,34 \%)$ patients over 18 years of age, with a UK mailing address; comparison with General Practice Patient Survey (GPPS); semistructured interviews with 24 pilot patients.

Results: Pilot patients were younger and more likely to be working than non-pilot patients at the same practices and reported generally more or at least as positive experiences than patients registered at the same practices, practices in the same PCT and nationally, despite belonging to subgroups of the population who typically report poorer than average experiences. Out of area patients who joined a pilot practice did so: after moving house and not wanting to change practice $(26.2 \%)$; for convenience $(32.6 \%)$; as newcomers to an area who selected a practice although they lived outside its boundary (23.6\%); because of dissatisfaction with their previous practice (13.9\%). Day patients attended primarily on grounds of convenience $(68.8 \%) ; 51.6 \%$ of the day patient visits were for acute infections, most commonly upper respiratory infections $(20.4 \%)$. Sixty-six per cent of day patients received a prescription during their visit.

Conclusions: Though the 12-month pilot was too brief to identify all costs and benefits, the scheme provided a positive experience for participating patients and practices.

\section{INTRODUCTION}

Giving patients more choice over where they access care has been central to reforms in England's National Health Service (NHS)
Strengths and limitations of this study

A strength of this study is that it adds to the very slender evidence either from the National Health Service (NHS) or other systems on the effects of widening patient choice of general practice, and specifically the effects of removing geographic boundaries. It reveals that patients reported high satisfaction with their experience in a short-term pilot of practice boundary removal and that most patients joined the pilot on grounds that the pilot practice was more convenient than their previous source of primary medical care.

- The main strength of the study is that it compares pilot patients' characteristics and experiences with those of all patients in the General Practice Patient Survey (GPPS) registered in the same practices and nationally. Survey response rates were similar to those for GPPS in the same PCTs. Semistructured interviews assisted in the development of pilot-specific survey questions and interpretation of the results.

- The study is limited by the structure of the pilot itself, which took place in relatively few, selfselected practices and could not be widely promoted, so it is not possible to estimate the likely patient participation rate were the scheme to be rolled out nationwide.

- In the 12-month pilot, it was not possible to identify the impact of removing practice boundaries on, for instance, referrals, overall use of primary and secondary care, costs to commissioners, equity of access or practice patient mix.

since the late 1990s. ${ }^{1-3}$ In normal circumstances, NHS patients are expected to seek their primary medical care from the practice with which they are registered and practices generally only accept patients who live within their geographic boundaries. Geographical boundaries in primary care were developed in the 1980s in response to the scattering of practices' patients which hampered home visits and linkages to community nursing organised on a patch basis.

A 2009 public consultation on increasing choice of general practitioner (GP) practice 
found that $18 \%$ of respondents were likely to register with a different practice within their local area (ie, register with a practice outside their current practice's boundary) if the option to do so was available. ${ }^{4}$ From 2012, general practices have been able to register patients that live beyond their 'normal' practice boundary as 'outer boundary' or 'fringe' list patients. However, practices are required to provide all care, including home visits, to these patients. ${ }^{5}$ In other circumstances outside the pilot, practices have the discretion to allow any patient to register, but may choose not to offer services such as home visits to distant patients.

As part of the Coalition government's pledge to increase patient choice and improve access, a 12-month choice of GP practice pilot was implemented in four primary care trusts (PCTs) from April 2012 to March 2013. The pilot allowed patients to either register at a volunteer practice as an out of area patient, with access to all primary medical services, except home visits or to see a GP or nurse as a day patient at a volunteer practice, for routine or non-urgent care, while remaining registered with their current GP practice. ${ }^{6}$ Unlike the 'outer boundary policy', home visits for out of area registered patients were to be provided by the home PCT. The pilot did not alter the existing arrangements for providing GP care to Temporary Residents or those requiring 'Immediate and Necessary' care. However, access was intended to differ in the pilot in that day patients were not required to show that they were living temporarily in the area and did not necessarily need to present with 'immediate and necessary' needs for care. In the case of out of area patients, the practice had access to patients' usual electronic records, but this was not so for day patients (information on whose visits were expected to be shared with the patients' registered practice). Participating practices were paid a $£ 12.93$ fee for each day patient visit. When an out of area patient registered with a pilot practice, the global sum funding for that patient was transferred to the pilot practice for the following year or the next payment period.

The pilot was intended to improve access for people such as workers finding it difficult to visit their regular practice during working hours, long-haul commuters or those wishing to register at another location (eg, near a family member). Very little is known of the consequences of removing or flexing practice boundaries. This paper describes patients' self-reported experiences of being an out of area patient or a day patient, drawn from the wider evaluation of the choice of GP practice pilot. $^{7}$

\section{METHODS}

\section{Routine data}

Basic quantitative profile data were collected for all 1358 (1108 out of area registered patients and 250 day patients) patients who used the pilot between April 2012 and March 2013. For out of area patients, limited administrative information was available through the National Health Authority Information System (NHAIS, now Connecting for Health) on age, gender, new practice code and the first 3-4 digits of the patient's home address post code. It was not feasible given the short duration of the pilot to negotiate permission to extract clinical data on out of area patients' use of their new practices from practice computer systems. For day patients, clinical data were available on the number of visits, along with the reason and consequence of each since all day patient visits were separately recorded and transmitted to the PCT for payment purposes. The local area team removed all identifiable information from the day patient visit forms before sharing it with the research team.

\section{Interviews with patients}

Semistructured telephone interviews were undertaken with 18 out of area registered patients and six day patients chosen, as far as possible, for maximum variation in terms of age and occupation, in order to explore why patients used the pilot scheme, their experiences and the perceived benefits and drawbacks of the scheme. Written informed consent was obtained based on a project evaluation information sheet for all patients interviewed. All interviews were recorded and transcribed. Transcripts were analysed thematically and coded in NVivo V.10.

\section{Patient survey}

We conducted a postal survey of all day $(64 / 188,34 \%$ response rate) and out of area registered (315/886, 36\%) patients aged 18 years and over and with a permanent address in the UK. Out of 1358 pilot patients, 284 pilot patients were not included in the survey, of these, 260 were aged under 18 ( $\mathrm{n}=222$ for out of area registered patients and $n=38$ for day patients) and 24 day patients did not have an available UK address. Pilot patients under 18 years were excluded because the GPPS is only administered to adults aged 18 years and over. The patient survey questionnaire was modelled on that used for the national GPPS; http://www.gp-patient.co.uk/ questionnaires/), and results were compared with GPPS results for year 7 wave 1 (July-September 2012) for the same PCTs and practices. In order to account for varying probabilities of selection and differential non-response (eg, by age and sex), the GPPS results were weighted (by Ipsos MORI, the organisation that carries out the GPPS) to be representative of all registered patients (aged 18+ years) within a practice, a PCT and nationally (http:// www.gp-patient.co.uk/results/download/_y6q2/y6w2_ AnnualTechnical.pdf). The data for the out of area registered patients were corrected for non-response and weighted so that the achieved sample matched the age distribution for all out of area patients aged 18+ years. Owing to small numbers, the day patient survey data were not weighted for non-response. Further details of the pilot patient survey methodology can be found in the full report of the evaluation ${ }^{7}{ }^{8}$ (http://www.piru.ac.uk/ 
assets/files/General\%20Practice\%20Choice\%20Pilot $\%$ 20Evaluation.pdf).

The survey data were analysed using SPSS V.20. Descriptive statistics are presented in table 1. All differences between the pilot patients and GPPS highlighted in the Results are statistically significant at the $95 \%$ level.

\section{Results}

\section{Pilot practice characteristics}

In the four PCTs, 43 general practices out of 269 eligible practices volunteered for the pilot (with 20/53 (38\%) of practices in Westminster, 7/63 (11\%) in Nottingham, 8/102 (8\%) in Manchester and 8/51 (16\%) in Salford). All participating practices were in urban areas. Pilot and non-pilot practices were similar in terms of list size, Quality and Outcome Framework (QOF) scores, and patient experiences and views in the GPPS (see the full report of the evaluation ${ }^{78}$ for further details about practice characteristics, list size and QOF score). There was no evidence that pilot practices were obviously 'better' practices.

\section{Pilot patient characteristics}

A total of 1108 patients registered at a pilot practice away from the area where they lived, while 250 patients saw a GP or nurse as a day patient. The vast majority of patients registered with, or attended, a pilot practice in Westminster, which accounted for $789 / 1108(71 \%)$ of out of area registered patients and 196/250 (78\%) of day patients, with the remaining $121 / 1108(11 \%)$ and $52 / 250(21 \%)$, respectively, in Nottingham, 114/1108 $(10 \%)$ and $0 / 250(0 \%)$, respectively, in Manchester and $84 / 1108(8 \%)$ and 2/250 (1\%), respectively, in Salford.

When compared to GPPS patients from the same practices, table 1 shows that out of area registered and day patients were much younger than other patients in the pilot practices $(64.1 \%$ of out of area registered and $67.3 \%$ of day patients were aged 18-34 compared with $33.3 \%$ of GPPS patients in pilot practices). They were also more likely to be in full-time work $(65.8 \%$ for out of area registered patients and $65.6 \%$ for day patients compared with $46.9 \%$ of GPPS patients in pilot practices). Among those in work, out of area registered and day patients tended to have a longer commute $(66.2 \%$ and $60 \%$ respectively had a journey to work time of half an hour or more compared with $34.6 \%$ of GPPS patients in pilot practices).

Out of area registered patients were more likely to be in education $(9.5 \%$ for out of area registered patients compared with $5.1 \%$ of GPPS patients in pilot practices) and less likely to be retired $(3.1 \%$ out of area registered compared with $13.3 \%$ GPPS patients in pilot practices).

Table 1 Demographic and health characteristics of out of area registered and day patient survey respondents compared with all GPPS patients in pilot practices

\begin{tabular}{|c|c|c|c|}
\hline Base: aged 18+ & $\begin{array}{l}\text { All GPPS* patients } \\
\text { in pilot practices, } \%\end{array}$ & $\begin{array}{l}\text { All OoA registered } \\
\text { patients, } \%\end{array}$ & $\begin{array}{l}\text { All day } \\
\text { patients, \% }\end{array}$ \\
\hline \multicolumn{4}{|l|}{ Gender } \\
\hline Men & 52.4 & 47.0 & 35.5 \\
\hline Women & 47.6 & 53.0 & 64.5 \\
\hline \multicolumn{4}{|l|}{ Age } \\
\hline 18-34 & 33.3 & 64.1 & 67.3 \\
\hline $35-54$ & 40.8 & 26.6 & 30.8 \\
\hline $55+$ & 25.9 & 9.2 & 1.9 \\
\hline \multicolumn{4}{|l|}{ Economic activity } \\
\hline Full-time work & 46.9 & 65.8 & 65.6 \\
\hline Part-time work & 10.8 & 5.4 & 8.2 \\
\hline Full-time education & 5.1 & 9.5 & 8.2 \\
\hline Unemployed & 9.7 & 9.0 & 6.6 \\
\hline Permanently sick & 6.7 & 1.4 & - \\
\hline Retired & 13.3 & 3.1 & 8.2 \\
\hline Other activity & 7.5 & 5.7 & 3.2 \\
\hline \multicolumn{4}{|l|}{ Journey time to work (for those in work) } \\
\hline Up to $30 \mathrm{~min}$ & 57.9 & 30.5 & 40.0 \\
\hline $30 \mathrm{~min}$ or more & 34.6 & 66.2 & 60.0 \\
\hline Live on site & 7.5 & 3.3 & - \\
\hline Is a parent (dependent children under 16 years) & 23.6 & 10.1 & 13.1 \\
\hline Is an unpaid carer & 15.1 & 3.8 & 8.3 \\
\hline Has longstanding health condition & 42.6 & 32.2 & 33.3 \\
\hline None of the listed medical conditions & 5.1 & 67.9 & 57.7 \\
\hline Basest & 4624 & 311 & 64 \\
\hline
\end{tabular}


Out of area registered patients were much less likely to have dependent children under 16 (10.1\% compared with $23.6 \%$ of GPPS patients in pilot practices) or to be unpaid carers (3.8\% compared with $15.1 \%$ of GPPS patients in pilot practices).

\section{Patients' reasons for taking part in the pilot}

We identified four types of out of area registered patients based on two survey questions that asked their reasons for participating in the pilot and for choosing the particular practice they were now registered with ( $\mathrm{see}^{8}$ for details of questions). About a quarter (26.2\%) had moved house and wished to stay with the same practice. About a quarter $(23.6 \%)$ had recently moved into the area and had registered with a local practice despite being outside its catchment. Around a third (32.6\%) chose their practice for convenience (eg, near their workplace); one such patient said the scheme was suitable "because this way, I don't have to take time off work to see my GP... now I can walk to the surgery within 10 min, it's extremely convenient" and "I can go and see my GP and be back at the office within half an hour, maybe $45 \mathrm{~min} .$. it is great for me, it is great for my employer" (patient interview, London). Some (13.9\%) chose their practice because they were dissatisfied with their previous GP or sought services that their previous practice could not provide. (A small proportion of out of area registered patients could not be classified, mostly because of missing data $(3.7 \%))$. Box 1 presents two different patient profiles from the qualitative interviews.

We identified three types of day patients based on survey questions about the main reason they had visited as a day patient instead of visiting their registered practice, whether they had tried to make an appointment at their registered practice, and how the practice they had visited compared with their registered practice (see ref. 8 for the questions). Day patients generally attended pilot practices because they were convenient $(68.8 \%)$. The second type would have been more appropriately categorised as temporary residents or requiring 'Immediate and Necessary' care. Nearly one in five $(18.8 \%)$ day patients fell into this type. This is consistent with qualitative interview findings that revealed some confusion among practices between the day patient option and existing provisions for urgent appointments in primary care. A small proportion of patients preferred a specific practice or a specific doctor (eg, if they had been registered at one practice before moving house and wanted to see their former GP while remaining registered with a local practice), received specialist care that their registered practice did not offer, or were not satisfied with the quality of care received at their registered practice $(7.8 \%)$. One such day patient said the day patient option made seeing a GP easier as "the opening hours are good and the first time I went before work which was really useful-8 o'clock, I think, and the second time I went in, somebody saw me right away" (patient interview, Nottingham). A small percentage of

\section{Box 1 Two out of area registered patient vignettes}

Male, age 28 years, in full-time employment, with chronic depression. He has been registered with the same practice for 6 years. He was invited to enter the pilot after revealing that he had moved out of the catchment area. He has a history of depression and felt he benefitted from staying at a practice where "they could see by my mood, my state of mind, that [an antidepressant] wasn't working -in fact, having a stimulant antidepressant as opposed to a sedative antidepressant was probably causing me to be worse." He wished to stay with this practice because he was satisfied with the service received, "it's about the individual, rather than just being a number, rather than just being a bit of funding."

Female, age 40 years, in full-time employment, with multiple chronic conditions.

She joined the pilot after enquiring at a practice near her office. She felt "the doctors where I live [are] absolutely horrendous and it would take me days or weeks to get an appointment." She reported health complications related to multiple chronic conditions "because I've seen a different doctor every time when I kept going back because obviously you can't get to see the same doctor when you ring up for emergency appointments. All of them did different things. They said different things. And advised me differently as well what to do." She felt her new practice was much better because "the nurses are fantastic. The GP, she sorted me out right away... they really take their time with you as well. Nothing's rushed..."

day patients could not be classified due to missing data $(4.7 \%)$. Most day patients $(77 \%)$ had not tried to make an appointment at their registered practice before their visit. Box 2 provides a vignette from a day patient interview.

\section{Conditions for which day patients consulted a pilot practice}

Half $(51.6 \%)$ of the visits were for acute infections, most commonly upper respiratory infections $(20.4 \%)$. Other acute conditions accounted for a further one in five (21.2\%) day patient visits, followed by medication issues $(7.6 \%)$ and chronic conditions $(5.2 \%)$. A relatively small percentage of visits did not require any treatment, or were to obtain reassurance or a second opinion $(8.4 \%)$. This pattern of use contrasts markedly with the overall

\section{Box 2 Day patient vignette}

Male, age 33 years, in full-time employment, no chronic conditions He learned about the pilot through his work and visited as a day patient for an acute infection. He found the service convenient because he could see a GP before, during or after work, in contrast to his registered GP, where he would need to take time off work or arrange to work at home because his train to work only ran during peak hours and it would be "a bit of a nightmare having to get back into work after doing something out of the ordinary." He felt the quality of service was comparable to his registered practice, but voiced concerns over data-sharing between the two practices, specifically "how are these GPs accessing my medical data to understand perhaps historic things that might aid in the resolution of a particular case diagnosis?" 
pattern in general practice where around $80 \%$ of GP consultations are for ongoing or chronic conditions. ${ }^{9}$

Two-thirds $(66 \%)$ of day patients received a prescription during their visit. Referrals were less common, with only one in $10(10.1 \%)$ day patients referred by the GP for tests or other services. Some referrals were for routine blood tests. Most referrals were for MRIs (for knee or back injuries) or physiotherapy; several day patients, many of whom presented in Westminster, used their private health insurance following a NHS GP referral.

Out of area registered patient experiences compared with all GPPS patients in the same practices

Out of area registered patients were more likely than all GPPS patients in the same pilot practices to describe the overall experience of making an appointment and their most recent visit to their practice as 'very good' $(47.1 \%$ and $57.3 \%$, respectively, of out of area registered compared with $37.4 \%$ and $47.1 \%$, respectively, of GPPS patients in pilot practices; see table 2). In general, out of area registered patients reported better experiences than non-pilot GPPS patients. This is notable given the much younger age profile of pilot patients and the wellsupported finding that younger patients tend to be more critical of their GP practice. ${ }^{10}$ They valued the quality of the service at their new practice and were happy with, and trusted, the care they received from GPs and nurses.

Patients who did not change practice held positive views of their GP practice and said the scheme had enabled them to stay with a practice that they trusted and which was sensitive to their health needs. Continuity

Table 2 Patient experience of the most recent GP appointment in the past 6 months and registered practice: views of registered and day patients compared with all GPPS patients in pilot practices

\begin{tabular}{|c|c|c|c|}
\hline $\begin{array}{l}\text { GPPS }^{*} \text { and OoA registered patier } \\
\text { aged } 18+\text {, who saw/spoket to } \\
\text { GP/nurse in past } 6 \text { months, DPs } \\
\text { registered with a GP practice }\end{array}$ & $\begin{array}{l}\text { GPPS patients in } \\
\text { pilot practices, } \%\end{array}$ & $\begin{array}{l}\text { OoA registered } \\
\text { patients, } \%\end{array}$ & DPs, \% \\
\hline \multicolumn{4}{|c|}{ Overall experience of making an appointment } \\
\hline Very good & 37.4 & 47.1 & 59.6 \\
\hline Fairly good & 39.4 & 37.2 & 27.7 \\
\hline Neither & 13.6 & 8.0 & 8.5 \\
\hline Fairly poor & 6.5 & 5.5 & 4.3 \\
\hline Very poor & 3.1 & 2.2 & - \\
\hline \multicolumn{4}{|l|}{ How good was the GP at... } \\
\hline \multicolumn{4}{|l|}{ Giving you enough time } \\
\hline Very good & 53.1 & 56.0 & 63.6 \\
\hline Good & 33.0 & 33.3 & 30.3 \\
\hline Neither & 9.1 & 5.4 & 3.0 \\
\hline Poor & 2.7 & 2.3 & 3.0 \\
\hline Very poor & 1.9 & 1.8 & - \\
\hline NA & 0.2 & 1.2 & - \\
\hline \multicolumn{4}{|l|}{ Treating you with care/concern } \\
\hline Very good & 51.6 & 59.3 & 60.6 \\
\hline Good & 32.2 & 29.4 & 27.3 \\
\hline Neither & 9.7 & 5.6 & 12.1 \\
\hline Poor & 3.4 & 3.1 & - \\
\hline Very poor & 2.3 & 1.9 & - \\
\hline NA & 0.7 & 0.8 & - \\
\hline \multicolumn{4}{|l|}{ Have confidence/trust in GP } \\
\hline Definitely & 64.7 & 71.1 & 63.6 \\
\hline To some extent & 28.2 & 22.2 & 30.3 \\
\hline Not at all & 5.4 & 3.7 & 3.0 \\
\hline Do not know & 1.8 & 3.1 & 3.0 \\
\hline \multicolumn{4}{|l|}{ Overall experience of practice } \\
\hline Very good & 47.1 & 57.3 & NA \\
\hline Fairly good & 41.6 & 36.0 & NA \\
\hline Neither & 7.0 & 3.2 & NA \\
\hline Fairly poor & 3.3 & 1.0 & NA \\
\hline Very poor & 1.0 & 2.6 & NA \\
\hline Bases $\ddagger$ & 4624 & 307 & 47 \\
\hline
\end{tabular}


of care was also important to those out of area patients who did not change practice and who had had a serious health incident, chronic condition, bereavement or major life transition.

Among those who had changed practice, three in five said their new practice was much $(46.5 \%)$ or somewhat $(14.5 \%)$ better than their previous one and one in four $(23.8 \%)$ that it was about the same. Only a small minority said it was somewhat $(3 \%)$ or much $(2.6 \%)$ worse than their previous practice. One interviewee who was dissatisfied with her previous practice and who had a positive reason for choosing an out of area practice said the pilot gave "access to a good quality practice which I wouldn't have if I could only register with the practice near where I live" ( patient interview, Nottingham).

\section{Day patient experiences}

Day patients were more likely than all GPPS patients in the same pilot practices to describe their overall experience of making an appointment as 'very good' $(59.6 \%$ of day patients compared with $37.4 \%$ of GPPS patients in pilot practices). The majority of day patients viewed the practice they visited as a day patient to be comparable to $(40 \%)$, or better than $(34.6 \%)$, their registered practice. Only $9.1 \%$ thought it was worse than their registered practice. In the interviews, day patients explained that their decision to visit a practice as a day patient was not a reflection of dissatisfaction with the type or quality of service at their registered practice, or even the superiority of the practice they visited as a day patient (they had very limited knowledge of the practice they had visited as a day patient) as much as the fact that the practice they visited as a day patient had been more convenient.

\section{Discussion}

\section{Statement of the principal findings}

The pilot attracted a relatively small proportion of practices in the four pilot PCTs. There was no evidence that these were better performing practices. About half of out of area registered patients had made a positive decision to change practice, with $32.6 \%$ choosing a practice for convenience and $13.9 \%$ moving because they were dissatisfied with their previous practice or attracted to some feature of the new practice. Of the rest, about a quarter joined the scheme because they chose to stay with a GP practice after moving out of the catchment area $(26.2 \%)$, while another quarter had moved to the area but had selected a practice which they would not normally have been able to register with $(23.6 \%)$. A few could not be classified due to missing data $(3.7 \%)$. Over two-thirds of day patients joined the scheme for reasons of convenience $(68.8 \%)$.

Participating patients were younger, more likely to be in work and had better self-reported health than other patients registered at the same practices. Despite these characteristics, out of area registered and day patients' assessments of their new practice and care were better than those reported nationally and in the same practices, and they generally expressed positive views of the scheme. These positive views are not surprising given the high proportion of pilot patients who had either stayed with an existing GP after moving house (presumably because they were satisfied with the practice), or had left a practice they were dissatisfied with, or had chosen their new practice for a particular reason. These findings suggest that the pilot of removing practice boundaries was successful in improving patient experience, at least in the short term. It is unclear whether these positive experiences could be maintained in the longer term.

\section{Strengths and limitations}

The main strength of this study is the ability to compare pilot patients' characteristics and experiences with those of all patients in the GPPS registered in the same practices and nationally. Survey response rates were equivalent to those for GPPS in the same PCTs. Another strength is that the semistructured interviews helped identify additional questions to include in the survey and, afterwards, helped with the interpretation of the survey results.

However, there are several limitations to the study, primarily due to the form of the pilot. First, the practices and patients were relatively few, self-selected and predominantly within Westminster PCT. Second, the pilot was not able to be widely promoted so patients often first learned about the scheme when they approached a new practice or notified their registered practice that they had moved house. As a result, it is impossible to estimate the likely patient participation rate were it rolled out nationwide and advertised. Third, in the limited time of the Pilot, it was not possible to analyse the practices from which the pilot participants came. With a small number of patients coming from a large number of practices, it was not feasible to collect data about patient experience from the 'losing' practices. Fourth, we are unable to interview staff at non-participating practices to ascertain why many practices had chosen not to participate.

Finally, although patient experiences were largely positive, a 12-month pilot was insufficient to reveal the full range of possible adverse consequences of this programme. For example, it was not possible to identify the impact of removing practice boundaries on factors such as referrals, overall use of primary and secondary care, costs of information transfer or increased care coordination, equity of access or practice patient mix. For instance, only two interviewed patients left the scheme during the pilot, one because she moved house (over 50 miles from the practice) and the other because the pilot practice did not meet his healthcare needs.

\section{Comparisons with existing literature}

This is the first study on the removal of practice boundaries in the English NHS. Previous efforts to provide first contact care more conveniently, such as at NHS walk in centres, have tended to have high unit costs due to low take up and have tended to become additions rather 
than substitutes for previous sources of care. ${ }^{3} 11-13$ The current pilot did not appear to incur significant additional costs, ${ }^{7}$ primarily because it used existing practices, but demand was modest (at least in the short period of the pilot) and it was run for too short a period to identify any substitution effects.

The findings resonate with what is known about patient behaviour in the UK where patients appear to value continuity of care highly, particularly those with long-term conditions, and in discrete choice experiments, prioritise continuity of care over reduced waiting times or more convenient appointments. ${ }^{14}$ This is consistent with our findings that one-quarter of out of area registered patients entered the pilot to avoid changing practice. On the other hand, convenience does matter when waiting times lengthen ${ }^{15}$ and this appeared to be the main motivation for a third of out of area registered patients and two-thirds of day patients joining the scheme.

Nearly one in seven pilot patients chose out of area registration because they were dissatisfied with their previous practice. This is consistent with the limited UK evidence on voluntary disenrollment from general practices which suggests that the small minority of patients who leave their current GP practice without moving house are leaving practices with relatively low levels of patient satisfaction, especially in terms of the quality of doctor-patient communication. ${ }^{16}$

\section{Implications for research and practice}

Since the pilot and its evaluation, NHS Employers, on behalf of NHS England, reached agreement with the British Medical Association (BMA), that all GP practices will be able to register patients outside their practice boundary on a voluntary basis in 2015. Practices are not obliged to provide home visiting for such patients and NHS England will be responsible for arranging in-hours urgent medical care for participating patients. The day patient option will not be provided. ${ }^{17}$ Given the small scale and limited duration of the pilot, the roll out should be accompanied by a longer term, fuller evaluation. It is possible that a range of drawbacks of the scheme will only emerge over a longer period $\left(\operatorname{see}^{18}\right.$ for a policy analysis on the impact of removing practice boundaries as one among a number of ways of improving access to urgent care in the English NHS). For example, when an out of area registered patient's circumstances change, how easily will they be able to find a practice near where they live? How easily will they be able to access urgent care near where they live while registered with a practice elsewhere? Could practices in commuter belts lose so many patients as to threaten their viability?

Acknowledgements The Policy Innovation Research Unit is funded by the Department of Health Policy Research Programme. The views expressed are those of the researchers alone and do not necessarily represent those of the Department of Health. The authors would like to thank BMJ Open's two reviewers (Rita Santos and Natasha Curry), as well as to Elizabeth Eastmure, Mylene Lagarde and Martin Roland, the other members of the team involved in the evaluation of the choice of GP practice pilot, for their advice and constructive criticism during the project.

Contributors ST and NM drafted the manuscript. ST was responsible for qualitative data collection. BE and ST were responsible for survey design and quantitative data analysis. Each of the authors was involved in data interpretation, critical review and refinement of the manuscript.

Funding This research was funded by the Policy Research Unit for Policy Innovation Research (102/0001), which is funded by the Department of Health Policy Research Programme.

Competing interests None.

Patient consent Obtained.

Ethics approval Ethical approval to undertake the study was granted by the Northern and Yorkshire Research Ethics Committee (REC reference 12/NE/ 0245) and the research ethics committee of the London School of Hygiene and Tropical Medicine. We obtained local research governance permission from each PCT we worked with.

Provenance and peer review Not commissioned; externally peer reviewed.

Data sharing statement No additional data are available.

Open Access This is an Open Access article distributed in accordance with the Creative Commons Attribution Non Commercial (CC BY-NC 4.0) license, which permits others to distribute, remix, adapt, build upon this work noncommercially, and license their derivative works on different terms, provided the original work is properly cited and the use is non-commercial. See: http:// creativecommons.org/licenses/by-nc/4.0/

\section{REFERENCES}

1. Mays N, Dixon A, Jones L. Understanding New Labour's Market Reforms of the English NHS. London: King's Fund, 2011.

2. Darzi A, Britain G. NHS next stage review: interim report: $\mathrm{COI}$ for the Department of Health. London: Department of Health, 2007.

3. Tan S, Mays N. Impact of initiatives to improve access to, and choice of, primary and urgent care in the England: a systematic review. Health Policy 2014;118:304-15.

4. Department of Health. Your choice of GP practice: a consultation on how to enable people to register with the GP practice of their choice. London: Department of Health, 2010.

5. Department of Health. Choice of GP practice: guidance for all PCTs-covering outer boundaries, open and closed lists and aspects of the patient choice scheme. London: Department of Health, 2012.

6. Department of Health. Choice of GP practice: the patient choice scheme. Secondary choice of GP practice: the patient choice scheme. London: Department of Health, 2012.

7. Mays N, Eastmure E, Erens B, et al. Evaluation of the choice of GP practice pilot, 2012-13: final report. Secondary Evaluation of the choice of GP practice pilot, 2012-13: final report. London: Policy Innovation Research Unit, 2014. http://www.piru.ac.uk/assets/files/ General\%20Practice\%20Choice\%20Pilot\%20Evaluation.pdf

8. Mays N, Eastmure E, Erens B, et al. Evaluation of the choice of GP practice pilot, 2012-13: final report, appendices. Secondary Evaluation of the choice of GP practice pilot, 2012-13: final report, appendices. London: Policy Innovation Research Unit, 2014. http://www.piru.ac.uk/assets/files/GP\%20Choice\%20Pilot\% 20Evaluation-Appendices.pdf

9. Wilson T, Buck D, Ham C. Rising to the challenge: will the $\mathrm{NHS}$ support people with long term conditions? BMJ 2005;330:657-61.

10. Kontopantelis E, Roland M, Reeves D. Patient experience of access to primary care: identification of predictors in a national patient survey. BMC Fam Pract 2010;11:61.

11. Coleman A, Checkland K, McDermott I, et al. The limits of market-based reforms in the NHS: the case of alternative providers in primary care. BMC Health Serv Res 2013;13(Suppl 1):S3.

12. O'Cathain A, Coster J, Salisbury C, et al. Do walk-in centres for commuters work? A mixed methods evaluation. Br J Gen Pract 2009;59:e383.

13. Coster J, O'Cathain A, Nicholl J, et al. User satisfaction with commuter walk-in centres. Br J Gen Pract 2009:59:e390.

14. Cheraghi-Sohi S, Hole AR, Mead N, et al. What patients want from primary care consultations: a discrete choice experiment to identify patients' priorities. Ann Fam Med 2008;6:107-15. 
15. Lagarde M, Erens B, Mays N. Determinants of the choice of GP practice registration in England: evidence from a discrete choice experiment. Health Policy 2014. In press.

16. Nagraj S, Abel G, Paddison C, et al. Changing practice as a quality indicator for primary care: analysis of data on voluntary disenrollment from the English GP Patient Survey. BMC Fam Pract 2013;14:89.
17. NHS Employers. Summary of 2014/15 GMS Contract negotiations. Secondary Summary of 2014/15 GMS Contract negotiations. 14 November 2013. http://www.nhsemployers.org/PayAndContracts/ GeneralMedicalServicesContract/GMSContractChanges/Pages/ Contractchanges201415.aspx\#8

18. Mays N, Tan S, Eastmure E, et al. Potential impact of removing general practice boundaries in England: a policy analysis. Health Policy, 2014;118:273-8. 